\title{
PROXIMAL THIGH PAIN AFTER FEMORAL NAILING
}

\section{CAUSES AND TREATMENT}

\author{
R. M. DODENHOFF, J. N. DAINTON， P. M. HUTCHINS
}

From the Royal Cornwall Hospital, Truro, England
We have reviewed retrospectively 80 patients who were treated for traumatic fractures of the femur with a Grosse-Kempf nail to assess the incidence and causes of persisting pain in the proximal thigh.

At a mean of 21 months after operation 33 patients had residual pain severe enough to interfere with their lifestyle or mobility. This was in the region of the scar on the greater trochanter in three-quarters of the patients. Only four showed no radiological abnormality. There was nonunion of the fracture in two, Paget's disease in one, breakage of the nail in two and prominence of the proximal locking screw in five, although we found no correlation between prominence of the nail and pain.

There was a strong relationship between pain and heterotopic ossification at the proximal end of the implant; this was present in $64 \%$ of the patients with pain as compared with those without pain $(p<0.001$, Mann-Whitney $U$ test). Of the 80 patients, 27 had the implant removed after 18 months, 17 of them because of pain. In six of these 17 , the pain was not relieved. Prominence of the nail proximally was not associated with pain, but protuberance of laterally-based proximal locking screws caused problems. We found a strong association between heterotopic bone formation and pain, but it is uncertain whether this is the true cause or merely an indication of some other factor such as traumatic damage to the glutei during insertion of the nail. Removal of the implant does not always cure such pain.

J Bone Joint Surg [Br] 1997;79-B:738-41.

Received 16 October 1996; Accepted after revision 4 April 1997
Intramedullary nailing is well established for the treatment of closed and some open fractures of the femur. ${ }^{1}$ This is usually done as a semiclosed procedure and allows early postoperative weight-bearing. For patients with multiple injuries it provides rapid stabilisation, makes nursing easier and reduces early mortality. ${ }^{2,3}$ The recognised complications include infection, iatrogenic fracture, fat embolism and delayed or nonunion, ${ }^{4-6}$ but little attention has been paid to persistent pain in the proximal femur after union. ${ }^{7}$ We aimed to assess the incidence of such pain and to investigate possible causes.

\section{PATIENTS AND METHODS}

We reviewed all patients treated for a traumatic fracture of the femoral shaft by Grosse-Kempf (GK) femoral nailing (Howmedica, London, UK) from January 1991 to December 1993. They were reviewed with their original case notes in a research clinic where they completed a questionnaire, and were examined and radiographed. The films were studied for evidence of nail protrusion, heterotopic bone formation and for implant failure or fracture. The total series included 117 femoral nailings in 115 patients. Of these, 19 pathological fractures secondary to tumour metastases were excluded, leaving 98 nails for study. The age distribution of these patients showed a peak at 21 to 30 years with a smaller peak in the ninth decade (Table I).

The cause of injury was a road-traffic accident in 65 , a severe fall in 29, sport in two and other injuries in two. Most were closed injuries, with eight Gustillo grade-I or grade-II open wounds. One quarter of the patients had
R. M. Dodenhoff, FRCS, Registrar

J. N. Dainton, FRCS G, Registrar

P. M. Hutchins, FRCS, FRCS Ed(Orth), Consultant Orthopaedic Surgeon Department of Orthopaedics and Trauma, Royal Cornwall Hospital, Infirmary Hill, Truro, Cornwall TR1 3LJ, UK.

Correspondence should be sent to Mr R. M. Dodenhoff, Senior Orthopaedic Registrar at Frenchay Hospital, Frenchay Park Road, Bristol BS16 $1 \mathrm{LE}, \mathrm{UK}$.

(C)1997 British Editorial Society of Bone and Joint Surgery 0301-620X/97/57345\$2.00
Table I. Age distribution of 96 patients having femoral nailing for traumatic fractures

\begin{tabular}{lc}
\hline Years & Number \\
\hline$<20$ & 16 \\
21 to 30 & 35 \\
31 to 40 & 14 \\
41 to 50 & 7 \\
51 to 60 & 5 \\
71 to 80 & 7 \\
81 to 90 & 10 \\
$>90$ & 2 \\
\hline
\end{tabular}




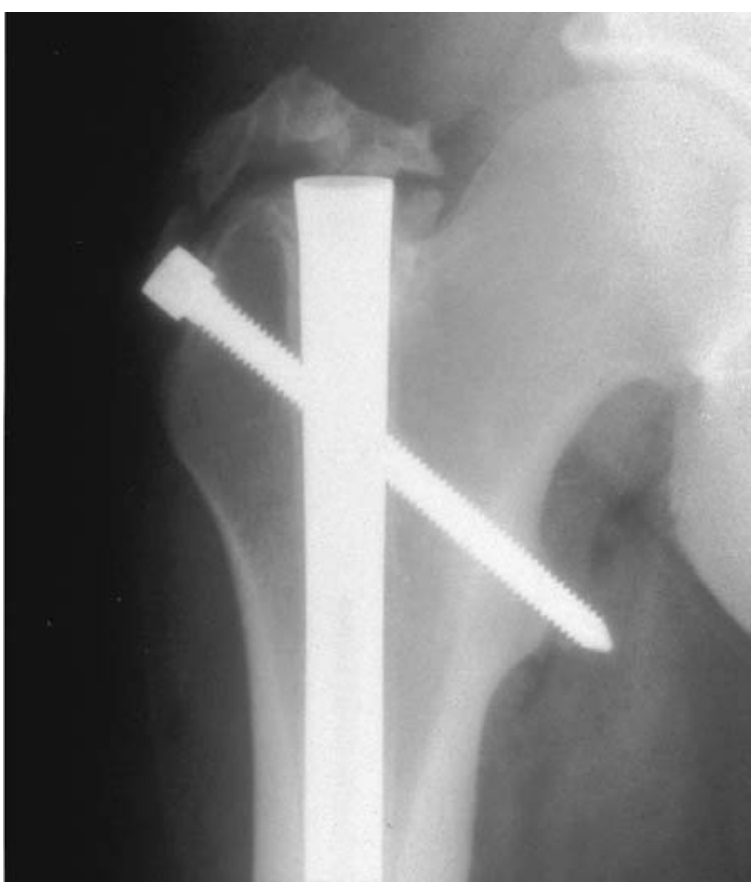

Fig. 1

Radiograph showing heterotopic ossification at the proximal end of the implant.

multiple injuries involving other long bones, or head, chest and abdominal injuries.

Statistical analysis. Results were analysed using the chisquared test with continuity correction and the MannWhitney $U$ test for analysis of non-parametric data. Population distributions were analysed using the Kolmorogov-Smirnov goodness-of-fit test to assess whether they were acceptably normal.

\section{RESULTS}

Five patients (six nailings) had died and 12 were not available for review, three being overseas and nine having moved to other regions of the UK. The remaining 80 patients were seen at a mean follow-up of 21 months (16 to 46).

The recorded complications included superficial infection (2), delayed or nonunion (3), and implant breakage (3). One patient had sustained an iatrogenic fracture of the greater trochanter, and one had a refracture due to a fall after the removal of the nail.

Residual pain. Of the 80 patients, 33 reported residual femoral pain sufficient to interfere with lifestyle or mobility $(41 \%)$. The pain was in the trochanteric region in 22 , the proximal thigh in nine and in the scar area in two. We found no relationship between age at injury and subsequent pain at any site (Mann-Whitney $U$ test, $\mathrm{p}=0.24$ ), but there was a significant difference between men and women $(59 \%$ of men complained, only $31 \%$ of women; chi-squared test, $p=0.03$ ). We found no clinical evidence of fascial defects,
Table II. Modified classification of heterotopic bone formation after femoral nailing

\begin{tabular}{lll}
\hline Grade & Bone & Range of movement \\
\hline 1 & Fleck & Full \\
2 & Cap $<1 \mathrm{~cm}$ & Full \\
3 & Cap $>1 \mathrm{~cm}$ & Full \\
4 & Large cap or bridging & Reduced \\
\hline
\end{tabular}

Table III. Associated findings in 33 patients with delayed pain

\begin{tabular}{lcc}
\hline Finding & Number & Percentage \\
\hline Heterotopic calcification grades 2 to 4 & 21 & 64 \\
Prominent locking screw & 3 & 9 \\
Implant fracture & 2 & 6 \\
Nonunion & 2 & 6 \\
Paget's disease of the femur & 1 & 3 \\
No abnormality detected & 4 & 12 \\
\hline
\end{tabular}

trochanteric bursitis or scar tethering.

Nail prominence. We found no significant relationship between nail projection above the bone and pain. The position of the top of the nail ranged from $20 \mathrm{~mm}$ below to $25 \mathrm{~mm}$ above the tip of the greater trochanter. The group with pain had a mean prominence of $2.57 \mathrm{~mm}$ as against 1.98 (not significant; Mann-Whitney $U$ test, $\mathrm{p}=0.145)$.

Heterotopic ossification. Heterotopic ossification at the proximal end of the implant was seen in 24 patients $(30 \%)$ (Fig. 1). We found a significant association between pain and such heterotopic ossification: in patients with pain, 21 of $33(64 \%)$ had ossification of grades 2 to 4 using a modification of the method of Marks, Paley and Kellam ${ }^{8}$ for classification (Table II); of patients with any heterotopic bone formation, 21 of $24(88 \%)$ had pain. The chisquared test showed that significantly more patients with heterotopic ossification of grades 2 to 4 reported pain than those with grades 0 to $1(\mathrm{p}<0.001)$. Patients reporting pain had significantly more heterotopic ossification than those without pain $(\mathrm{p}<0.001$, Mann-Whitney $\mathrm{U}$ test $)$ (Table III).

Locking screw prominence. Three patients complained of pain at the site of the proximal locking screw which, in the GK nail, is passed obliquely and inferiorly from a position on the lateral aspect of the greater trochanter. In two of these the screw had not been fully inserted and in the third patient there was little subcutaneous tissue. All three had relief of pain after removal of the implant.

Miscellaneous. Of the remainder of the group with delayed pain, two patients had fracture of the implant at the level of the longitudinal slot, and have not yet been revised. A further two returned with pain in the thigh after they had been discharged and were found to have nonunion. They have been treated by exchange nailing. The final four patients had no radiological abnormality which might explain the residual pain. This group included two 
Table IV. Relationship between radiological abnormalities, pain, and pain relief after implant removal in 80 patients*

\begin{tabular}{|c|c|c|c|c|c|}
\hline Group & $\begin{array}{l}\text { Painfree } \\
(n=47)\end{array}$ & $\begin{array}{l}\text { Nail removed } \\
(n=10)\end{array}$ & $\begin{array}{l}\text { Delayed pain } \\
(\mathbf{n}=\mathbf{3 3})\end{array}$ & $\begin{array}{l}\text { Nail removed } \\
(\mathrm{n}=17)\end{array}$ & $\begin{array}{l}\text { Pain relief } \\
(n=11)\end{array}$ \\
\hline Heterotopic ossification grades 2 to 4 & 3 & 2 & 21 & 13 & 7 \\
\hline Prominent proximal screw & 1 & - & 3 & 3 & 3 \\
\hline Nail fracture & - & - & 2 & - & - \\
\hline Occult nonunion & 1 & - & 2 & - & - \\
\hline Paget's disease & - & - & 1 & - & - \\
\hline No radiological abnormality & 42 & 8 & 4 & 1 & $1 \dagger$ \\
\hline
\end{tabular}

patients with unlocked nails.

Implant removal. In 27 of the 80 patients the nail had been removed after 18 months. In 17 pain was cited as the main reason for wanting removal of the implant, and of these patients 13 had heterotopic ossification of grades 2 to 4 . In six of these, however, the pain did not settle after removal of the implant. At removal the local bone was biopsied but histological examination showed no abnormal features.

Of the remaining four patients whose implant had been removed for pain, three had prominent proximal locking screws and one an unlocked nail; pain settled after removal of the implant in all four. Table IV summarises the relationship between radiological abnormalities, delayed pain and its relief after removal of the implant.

\section{DISCUSSION}

Locked femoral nailing is now regarded as the method of choice for the fixation of most femoral fractures. ${ }^{1}$ Over $40 \%$ of patients report pain after locked femoral nailing; ${ }^{7}$ this may be severe enough to interfere with activities of daily living.

We found a radiological abnormality in most patients who had such pain. Causes such as nonunion, Paget's disease, and nail fracture are usually obvious, and we found that the proximal locking screw of this nail tended to be very prominent, especially in a thin patient. Countersinking of the head of the proximal screw would make it less prominent, but this may hamper the later removal of the nail. Prominence of the proximal end of the nail itself was not associated with proximal thigh pain. We used few unlocked nails and are unable to comment on a possibly different incidence of proximal thigh pain.

Some of the other radiological abnormalities which we saw are difficult to correlate with persisting pain. Heterotopic bone formation is common after total hip arthroplasty, but its development at the upper end of a reamed femoral intramedullary nail has received less attention, although it was described by Kuntscher himself. ${ }^{9} \mathrm{He}$ believed that the new bone formation was due to the prominence of the nail, a haematoma and possibly an osteogenic factor transferred from the medullary canal. The heterotopic bone after semiclosed intramedullary nailing is seen at the site of the operation rather than at the level of the fracture.

Moderate to severe heterotopic bone formation has been reported in $20 \%$ of femoral nailings. ${ }^{9,10}$ In our series, $30 \%$ of patients showed ectopic bone at the end of the implant; of these $88 \%$ had significant pain. The overall incidence of pain in our study is similar to that in other reports, ${ }^{7}$ but the strong association with heterotopic ossification has not been noted previously. Whether this is the cause of the pain or whether it merely indicates injury to the soft tissues at the time of insertion of the nail is uncertain. We did not find that proximal prominence of the nail itself was a significant factor for heterotopic bone formation.

The reason for this new bone formation is not clear. Heterotopic bone formation is more common after a transtrochanteric approach to the hip than after an anterolateral approach. ${ }^{11}$ Bone reamings are known to be highly osteogenic. ${ }^{12}$ Both the above factors apply during nail insertion. There is also a higher incidence of heterotopic bone formation in patients with head injuries and those who have needed prolonged ventilation; ${ }^{13}$ this may be relevant in view of the high number of patients with polytrauma in our study.

The association of pain after fracture healing with heterotopic bone has led us to examine the effect of different types of irrigation after reaming to prevent seeding of osteogenic material, the use of a new design of tissue protector to decrease soft-tissue damage, and the effect of prophylaxis with indomethacin.

Although none of the authors have received or will receive benefits for personal or professional use from a commercial party related directly or indirectly to the subject of this article, benefits have been or will be received but are directed solely to a research fund, educational institution, or other non-profit institution with which one or more of the authors is associated.

\section{REFERENCES}

1. Bucholz RW, Jones A. Fractures of the shaft of the femur. $J$ Bone Joint Surg [Am] 1991;73-A:1561-6.

2. Johnson KD, Cadambi A, Seibert GB. Incidence of adult respiratory distress syndrome in patients with multiple musculoskeletal injuries: effect of early operative stabilization of fractures. J Trauma 1985;25: 375-84.

3. Meek RN, Vivoda EE, Pirani S. Comparison of mortality of patients with multiple injuries according to type of fracture treatment: a retrospective age- and injury-matched series. Injury 1986;17:2-4. 
4. Winquist RA, Hansen ST Jr, Clawson DK. Closed intramedullary nailing of femoral fractures: a report of five hundred and twenty cases. J Bone Joint Surg [Am] 1984;66-A:529-39.

5. Simonian PT, Chapman JR, Selzuick HS, et al. Iatrogenic fractures of the femoral neck during closed nailing of the femoral shaft. $J$ Bone Joint Surg [Br] 1994;76-B:293-7.

6. Pell ACH, Christie J, Keating JF, Sutherland GR. The detection of fat embolism by transoesophageal echocardiography during reamed intramedullary nailing: a study of 24 patients with femoral and tibial fractures. J Bone Joint Surg [Br] 1993;75-B:921-5.

7. Bednar DA, Ali P. Intramedullary nailing of femoral shaft fractures: resorption and return to work. Can J Surg 1993;36:464-6.

8. Marks PH, Paley D, Kellam JF. Heterotopic ossification around the hip with intramedullary nailing of the femur. J Trauma 1988;28: 1207-13.
9. Bick EM. The intramedullary nailing of fractures by G. Kuntscher. Translation of an article in Arch Klin Chir, 200, 443, 1940. Clin Orthop 1968;60:5-12.

10. Brumback RJ, Wells JD, Lakatos R, et al. Heterotopic ossification about the hip after intermedullary nailing for fractures of the femur. J Bone Joint Surg [Am] 1990;72-A:1067-73.

11. Vicar AJ, Coleman CR. A comparison of the anterolateral, transtrochanteric and posterior surgical approaches in primary total hip arthroplasty. Clin Orthop 1984;188:152-9.

12. Paley D, Young MC, Wiley AM, Fornasier V, Jackson RW. Percutaneous bone marrow grafting of fractures and bony defects: an experimental study in rabbits. Clin Orthop 1986;208:300-12.

13. Garland DE, Blum CE, Waters RL. Periarticular heterotopic ossification in head-injured adults: incidence and location. J Bone Joint Surg [Am] 1980;62-A:1143-6. 